\title{
Surface velocity estimations of ice shelves in the northern Antarctic Peninsula derived from MODIS data
}

\author{
CHEN Jun ${ }^{1,2}$, "KE Changqing ${ }^{1,2}$, ZHOU Xiaobing ${ }^{3}$, SHAO Zhude ${ }^{1,2}$, \\ LI Lanyu ${ }^{1,2}$
}

1. Jiangsu Provincial Key Laboratory of Geographic Information Science and Technology, Nanjing University, Nanjing 210023, China;

2. Key Laboratory for Satellite Mapping Technology and Applications of State Administration of Surveying, Mapping and Geoinformation of China, Nanjing University, Nanjing 210023, China;

3. Department of Geophysical Engineering, Montana Tech of the University of Montana, Butte, MT 59701, USA

\begin{abstract}
The ice shelves in the northern Antarctic Peninsula are highly sensitive to variations of temperature and have therefore served as indicators of global warming. In this study, we estimate the velocities of the ice shelves in the northern Antarctic Peninsula using co-registration of optically sensed images and correlation module (COSI-Corr) in the Environment for Visualizing Images (ENVI) based on Moderate Resolution Imaging Spectroradiometer (MODIS) images during 2000-2012, from which we conclude that the ice flow directions generally match the peninsulas pattern and the crevasse, ice flows mainly eastward into the Weddell Sea. The spatial pattern of velocity field exhibits an increasing trend from the western grounding line to the maximum at the middle part of the ice shelf front on Larsen $C$ with a velocity of approximately $700 \mathrm{ma}^{-1}$, and the velocity field shows relatively higher values in its southerly neighboring ice shelf (e.g. Smith Inlet). Additionally, ice flows are relatively quicker in the outer part of the ice shelf than in the inner parts. Temporal changes in surface velocities show a continuous increase from 2000 to 2012. It is worth noting that, the acceleration rate during 2000-2009 is relatively higher than that during 2009-2012, while the ice movement on the southern Larsen C and Smith Inlet shows a deceleration from 2009 to 2012.
\end{abstract}

Keywords: surface velocities; ice shelf; northern Antarctic Peninsula; MODIS; spatiotemporal variations

\section{Introduction}

The Antarctic ice sheet affects global eco-environment and the level of human future devel-

Received: 2015-05-03 Accepted: 2015-07-31

Foundation: National Nature Science Foundation of China, No.41371391; Chinese National Antarctic and Arctic Research Expedition, No.CHINARE2015-02-02; Specialized Research Fund for the Doctoral Program of Higher Education of China, No.20120091110017; A Project Funded by the Priority Academic Program Development of Jiangsu Higher Education Institutions (PAPD). And this work was partially supported by Collaborative Innovation Center of Novel Software Technology and Industrialization

Author: Chen Jun, PhD Candidate, specialized in Remote Sensing and glaciology. E-mail: gischen@126.com

"Corresponding author: Ke Changqing, Professor, E-mail: kecq@nju.edu.cn 
opment, and its surface velocity is a direct signal of the response of ice shelves to climate change. The ice shelves in the northern Antarctic Peninsula are highly sensitive to variations in temperature and have therefore served as indicators of global warming. The lost area of the 12 ice shelves on the Antarctic Peninsula over the past five decades was more than $28,000 \mathrm{~km}^{2}$ (Cook and Vaughan, 2010), four of these ice shelves on the northeast coast of the Antarctic Peninsula have disintegrated between 1986 and 2002 (Skvarca, 1993; Rott et al., 1996; Rack and Rott, 2004). The disintegration and subsequent rapid disappearance of these ice shelves have attracted attention to the status of the other ice shelves in the northern Antarctic Peninsula (Rott et al., 2011; Rack et al., 2000). Over the past two decades, the Larsen C ice shelf has been thinning (Shepherd et al., 2003), but otherwise did not exhibit signs of obvious retreat (Glasser et al., 2009). The surface morphology and extent of Larsen $\mathrm{C}$ and southerly neighbours do not suggest any dramatic changes at present. However, the average surface temperature isotherm of $-9^{\circ} \mathrm{C}$ (Morris and Vaughan, 2003) represents an approximate limit for ice shelf viability (Broeke, 2005), and crosses the northwestern region of Larsen C, and it emphasizes the uncertainty of the above ice shelves in terms of its stability and mass balance (Jansen et al., 2010). The velocities of ice shelves have changed frequently and greatly in response to the atmospheric warming over the past century (Vaughan et al., 2003). Several disintegrated ice shelves in the northern Antarctic Peninsula underwent great changes in speed before they collapsed (Haug et al., 2010), e.g. Larsen A accelerated in motion by up to $15 \%$ from $1975-1986$ to $1986-1989$ and accelerated by $10 \%$ from 1986-1989 and 1988-1989 to 1992-1993 (Bindschadler et al., 1994; Rack et al., 1999). Since the discharge of ice is largely dependent on the glacier velocity, with accelerated or decelerated motion indicating an alteration of the ice mass balance (Nakamura et al., 2007; Strozzi et al., 2008; Scambos et al., 2011). Surface velocity is thus an important parameter in estimating ice flux into ocean and thus the mass balance of Antarctic ice shelves (Rosenau et al., 2012). Therefore, accurate mapping of the surface velocities in the northern Antarctic Peninsula ice shelves is important for understanding Antarctic glacier dynamics.

Field observation and remote sensing are two main methods for monitoring glacier velocities. While in the past several decades, global positioning system (GPS) has replaced stake measurement as a main tool to conduct field measurements in Antarctic (Manson et al., 2000). However, there are always substantial limitations in field observation such as high costs and harsh environment (Urbini, 2008). On the other hand, microwave and optical remote sensing allow for rapid velocity measurement of Antarctic glacier movement (Scheuchl et al., 2012; Osmanoglu et al., 2013). InSAR (synthetic aperture radar (SAR) interferometry) is a valuable technique for studying the Antarctic glacier dynamics due to its high sensitivity to terrain deformations (Ke et al., 2013), which has been successfully used by many researchers to drive velocity field on Antarctic ice sheet and to generate a digital mosaic of ice motion over the entire continent (Rignot et al., 2011). It is worth noting that, the ice shelves in the northern Antarctic Peninsula suffered surface melt. Unlike their neighbors farther south (Griggs and Bamber, 2009), the frequent surface melting events of ice shelf are likely to cause decorrelation between InSAR images, making it difficult to form interferograms. Alternatively, co-registration of optically sensed images and correlation (COSI-Corr) is a methodology to retrieve ground surface deformation, ice flows, slow landslides, etc. from multi-temporal optical remotely sensed images by accurate orthorectification, co-registration, and correlation (Leprince et al., 2007). Using COSI-Corr, the large 
amount of optical remote sensing images with a long history can be used for glaciology study. The accuracy of feature tracking is determined by the quality (less cloud, accurate positions, etc.) and spatial resolution of the optical imagery used. Therefore, for the surface velocity monitoring of the Antarctic glaciers using high-resolution optical images, such as Landsat Thematic Mapper/Enhanced Thematic Mapper (TM/ETM) (Berthier et al., 2003), Advanced Spaceborne Thermal Emission and Reflection Radiometer (ASTER) (Tiwari et al., 2014), and the Systeme Probatoire d'Observation dela Tarre (SPOT) (Ahn and Howat, 2010) are usually used. Nevertheless, the ice shelves in the northern Antarctic Peninsula have high surface velocities, MODIS images of 250-m resolution should meet the matching requirement of feature tracking. Haug et al. (2010) showed that MODIS data were suitable to accurately retrieve velocity field on Antarctic ice shelves by comparing surface ice velocities derived from TM/ETM images with velocities derived from MODIS images. In addition, there are at least two advantages by applying medium-resolution images: (1) the frequent coverage of multiple times per day in the Antarctic Peninsula increases the chance of more high-quality images; and (2) because of its large coverage of a single MODIS image, the velocity field derived is almost for the same time everywhere within a large area. The problem of temporal mismatch is much less severe than a mosaicked image from multiple images of high resolution acquired at different dates to cover the same large area.

There are two main purposes for this study. The first one is to demonstrate that MODIS images can be used to estimate the surface velocity of the Antarctic ice shelves where there have significant large-scale flowing texture and with good contrast for feature tracking, which can be served as a supplement to the existing methods. We will use COSI-Corr module in the Environment for Visualizing Images (ENVI) (Kääb and Vollmer, 2000; Ayoub et al., 2009) to estimate ice shelves surface velocities and analyse associated spatiotemporal variations during 2000-2012 using MODIS images. To date, most ice movement studies are focused on correlation methods or individual shelves over relatively short time intervals. In this study, a longer time-series of surface velocity estimations of ice shelves will be compiled, and we will analyse the temporal characteristics of ice shelves in the northern Antarctic Peninsula in details. The other purpose is to reveal the overall spatiotemporal characteristics and trends from the observed surface velocities. It may be useful for those who are interested in long-term and large-scale assessment of ice flowing.

\section{Study area}

The study area mainly covers the Larsen C Ice Shelf and its neighbours farther south (Figure 1), located on the eastern side of Oscar II, Foyn, Bowman as well as Wilkins Coast. It is confined by the Jason Peninsula in the north and extends to Dolleman Island and Boggs Cape. The flow units of the main ice shelf originate from the Cabinet Inlet, Mill Inlet, Mobiloil Inlet and Smith Inlet, as well as the Revelle Inlet.

The large pixels $(250 \mathrm{~m} \times 250 \mathrm{~m})$ may smooth over small features that might be used for feature tracking such as those within grounding line areas or inlet glaciers where ice flows are confined in narrow valleys (Rott et al., 2011). For such cases, the texture in grounding line areas and inlet glaciers may not be observed and matched. Therefore, MODIS images may not be suitable to accurately retrieve velocity field within the grounding line areas. For successful feature tracking, the image pixel should be smaller than the surface displacements 
during the observation period, the time interval of image pair should be 2.2-3.7 years. The displacement between features over $250 \mathrm{~m}$ during the observation period on images corresponds to a surface velocity greater than $113 \mathrm{ma}^{-1}$. Combining the two conditions mentioned above, we will only consider the floating ice areas with relatively high velocities or high quality of features in MODIS images, and mask out the grounding line areas where there is a lack of large-scale structural features for tracking. To define the study area, we will use the ice shelf fronts in 2000, 2003, 2006, 2009 and 2012, respectively, and the western edges to form the boundary of the study area (Figure 2). Once the boundary is defined, the total area of the study region is found to be approximately $46,000 \mathrm{~km}^{2}$.

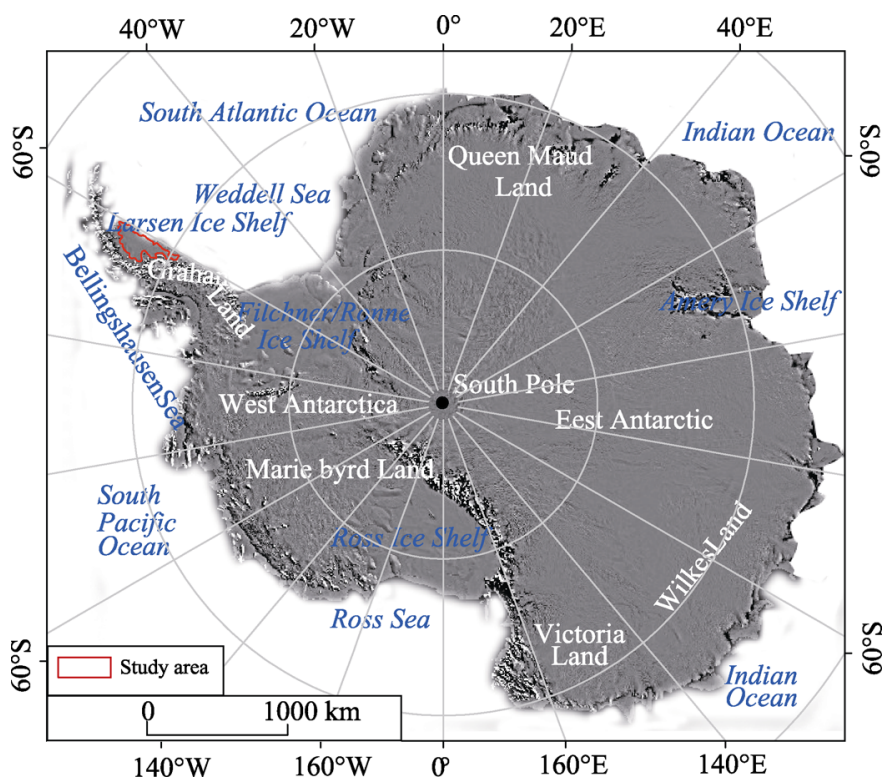

Figure 1 Location of the study area in the Antarctica. The underlying images are MODIS mosaics that are preprocessed by Haran et al. (2005).

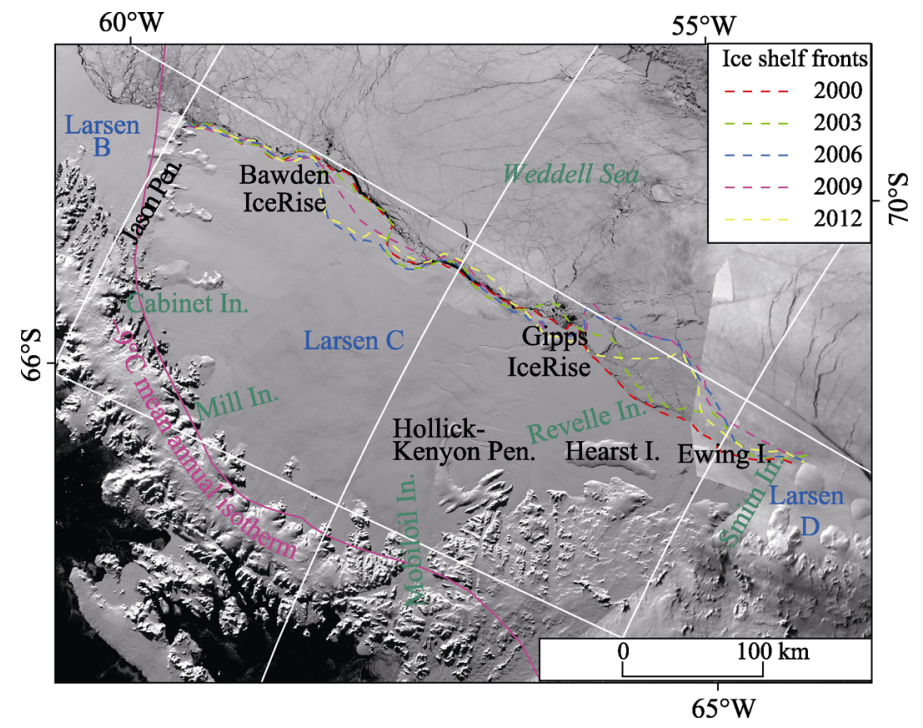

Figure 2 The ice shelf fronts in 2000, 2003, 2006, 2009 and 2012, respectively. The underlying images are MODIS mosaic in 2000. 


\section{Data sources}

The input optical images to the COSI-Corr module in ENVI for glacier dynamics study need to meet two requirements: (1) at least two images at different times are needed so as to observe the significant flowing texture, and (2) the image pixel should be smaller than the surface displacements of ice shelf during the observation period. Once the requirements are met, the cross-correlation calculation based on repeat optical images can be carried out (Erten et $a l ., 2012)$. The average velocities of ice shelves in the northern Antarctic Peninsula are significantly higher than that of tributary glaciers. Thus, MODIS images of 250-m resolution should meet the matching requirement of feature tracking within ice shelves. MODIS images in polar regions have the merits of frequent coverage (e.g. several times per day) and with a relatively long history, making it easy to select quality images for long-term velocity estimation on a large scale.

The MODIS data are provided by US National Aeronautics and Space Administration (NASA). Based on the satellite platforms (either Terra or Aqua), the data products are named differently: MOD02 for MODIS on Terra and MYD02 for MODIS on Aqua. MODIS L1B product consists of calibrated radiances at different resolutions (i.e., $1 \mathrm{~km}, 500 \mathrm{~m}$, and $250 \mathrm{~m}$ ) and onboard calibrator/engineering data. These data are "scientific data". The position information for each pixel is "geographic data". We separated geographic data from the scientific data so that the scientific data images can be manipulated while keeping the geographic data intact. After processing, the scientific data are connected back to the geolocation data for geocoding. The final images (e.g. the pixel values are reflectance) have the geolocation accuracy of $50 \mathrm{~m}$ at nadir (Wolfe et al., 2002). It is higher than that of TM/ETM images, whose geolocation accuracy is $250 \mathrm{~m}$ (NASA, 1996). Here, we select band 1 images (e.g. spectral range: 620-670 nm; spatial resolution: $250 \mathrm{~m}$ ) of MOD02 with minimum cloud and high quality of features in 2000, 2003, 2006, 2009 and 2012, respectively (Table 1). The displacements were extracted from the different image pairs with different time interval and the flowing velocity was then calculated. Finally, the velocity field over the Larsen $\mathrm{C}$ and southerly neighbours was generated by digital mosaicking.

Table 1 MODIS L1B images used for the velocity estimation and their parameters

\begin{tabular}{|c|c|c|c|c|}
\hline Period1 & Period2 & Period3 & Period4 & Period5 \\
\hline 27-MAR-2000 (13:15) & 10-FEB-2003 (12:45) & 3-JAN-2006 (12:30) & 8-APR-2009 (14:15) & 19-JAN-2012 (13:25) \\
\hline 29-MAR-2000 (13:05) & 20-MAR-2003 (13:45) & 5-JAN-2006 (14:45) & 1-JAN-2009 (13:10) & 25-JAN-2012 (12:50) \\
\hline 24-AUG-2000 (14:15) & 8-APR-2003 (14:15) & 7-JAN-2006 (14:20) & & 21-FEB-2012 (14:10) \\
\hline 26-AUG-2000 (15:40) & 18-APR-2003 (14:50) & 20-FEB-2006 (12:15) & & 19-AUG-2012 (13:50) \\
\hline 24-SEP-2000 (11:55) & 11-DEC-2003 (14:50) & $10-N O V-2006(12: 35)$ & & 23-AUG-2012 (13:25) \\
\hline
\end{tabular}

The ASTER Global Digital Elevation Model (GDEM) were generated based on paired stereo images in the near-infrared band obtained using the vertically downward and rear-view imaging sensors of ASTER onboard Terra (Cook et al., 2012). These data have a spatial resolution of $30 \mathrm{~m}$ and are horizontally georeferenced to Universal Transverse Mercator Projection/World Geodetic System 1984 (UTM/WGS84) with a coverage range of all land areas between $83^{\circ} \mathrm{N}$ and $83^{\circ} \mathrm{S}$, corresponding to $99 \%$ of the land surface of the Earth (Hirt et al., 2010). We calculated the three-dimensional velocities based on the slope and aspect for the ice shelves extracted from the ASTER GDEM data. 


\section{Methods}

\subsection{Feature tracking}

The COSI-Corr module in ENVI uses at least two MODIS images at different times for cross-correlation calculation. The early images (the reference images) are divided into matching windows (reference chip) by grids; each window of the same size (search chip) searches for the highest correlation in late images (the search images). The available cross-correlation algorithms include normalized cross-correlation (NCC) (Kaufmann and Ladstädter, 2003), orientation correlation (OC) (Fitch et al., 2002), cross-correlation operated in the Fourier domain (CCF) (McClellan et al., 2003), and the cross-correlation coefficient (CCC) (Evans, 2000). We identify the spatiotemporal patterns of surface movement of ice shelves for long-term velocity estimation on a large scale. Thus, the simplicity of CCC should meet the criteria of cross-correlation calculation. In this study we calculate the CCC as follows:

$$
C C C(u, v)=\frac{\sum_{y=1}^{M} \sum_{x=1}^{N}[f(x, y)-\bar{f}]}{\left\{\sum_{y=1}^{M} \sum_{x=1}^{N}[f(x, y)-\bar{f}]^{2}\right\}^{1 / 2}} \cdot \frac{[g(x+u, y+v)-\bar{g}(u, v)]^{2}}{\left\{\sum_{y=1}^{M} \sum_{x=1}^{N}[g(x+u, y+v)-\bar{g}(u, v)]^{2}\right\}^{1 / 2}}
$$

where $f(x, y)$ and $g(x, y)$ indicate the pixel value of feature points in the reference chip and search chip, respectively. $u, v$ are surface offsets between reference chip of the reference image and search chip of the search image. $\bar{f}, \bar{g}(u, v)$ are mean pixel values of reference chip and search chip. $N, M$ indicate the scopes of a chip. $[f(x, y)-\bar{f}]$ and $[g(x+u, y+v)-\bar{g}(u$, $v)$ ] indicate the pixel reflectance value that has the highest deviation between the means of all pixels which shall be identified as feature points from the chip. When difference in the overall reflectance of two images acquired at different times occurs, e.g., due to topography, orbits and altitude, the CCC automatically reduces the impact since only the deviation values rather than the absolute reflectance values are used. Nonetheless, this algorithm could cause mismatch since the criteria to identify a feature point is too restrictive. In the CCC algorithm, the calculated results are recorded using the S-N and W-E surface offsets, then we calculate the direction of ice shelf movement as follows:

$$
\theta=90\left(2\left(1+\frac{|u|}{\pi u} \sin ^{-1} \frac{v}{\sqrt{u^{2}+v^{2}}}\right)-\frac{|v|}{v}\left(\frac{|u|}{u}+1\right)\right)
$$

where $\theta$ represents direction of ice flow within $0-360^{\circ} ; u$ is the W-E displacement, where from west to east is defined as positive; and $v$ is the $\mathrm{S}-\mathrm{N}$ displacement, where from south to north is defined as positive. Additionally, the signal-to-noise ratio (SNR) is used as a measure that expresses the reliability of a match to discriminate between correct and erroneous matches (Huang and Li, 2011), we set the threshold to be SNR $<0.8$ and remove all results with SNR $\geqslant 0.8$ to ensure quality in selecting matching pairs.

The parameter setting is an important step of COSI-Corr (Xu et al., 2011). The window size should be set small enough to prevent different ice displacements from being included in the same window, for areas with good contrast, and a window of $15 \times 15$ pixels can give 
correct matches based on MODIS images. However, the root mean square error (RMSE) of the displacement measurements over bare rocks is relatively high (Haug et al., 2010). Thus, to ensure the accuracy of calculations, the window size should be large enough and more pixels should be calculated. Different window sizes lead to calculated results with different SNR and RMSE. When the reference window (chip) is set to below $10 \times 10$ pixels, the noise from mismatches play a key role (Huang and $\mathrm{Li}, 2011$ ), which shows random results; while when SNR increases gradually as window size grows, the velocities become stable. Meanwhile, the RMSE of the measurements increases with growth of size. Therefore, the reference window should be selected with a moderate size. Additionally, the window setting is according to the displacement of ice sheet or glacier, the highest velocity of ice shelves in the northern Antarctic Peninsula is approximately $700 \mathrm{ma}^{-1}$. Thus, Haug et al. (2010) used matching windows of $44 \times 44$ pixels $(11,000 \mathrm{~m})$ for the MODIS images and $350 \times 350$ pixels $(10,500 \mathrm{~m})$ for the Landsat images in Larsen $\mathrm{C}$ ice shelf. Based on lots of experiments in the present study, the reference window (chip) size for cross-correlation calculation is set to $36 \times 36$ pixels, corresponding to a ground area of $9000 \mathrm{~m} \times 9000 \mathrm{~m}$, which can provide surface velocity with the best precision on the study area and the search area of the search image is set to $108 \times 108$ pixels, corresponding to a ground area of $27,000 \mathrm{~m} \times 27,000 \mathrm{~m}$.

\subsection{Error analysis}

The method of using CCC and MODIS images to derive ice velocity field on ice shelves can achieve satisfactory results; however, the velocity field derived is relatively coarse and noisy compared to other methods such as InSAR (Nakamura et al., 2007), feature tracking based on high-resolution optical image (Roland and Jason, 2013), and GPS (Testut et al., 2003). There are several sources of errors in the correlation calculations. For instance, the geolocation accuracy for MODIS imagery is $50 \mathrm{~m}$ (Wolfe et al., 2002), nonetheless, we find that the registration accuracy of image-to-image is better than $10 \mathrm{~m}$ from some primary experiments, and this results in an uncertainty of $\pm 10 \mathrm{~m}$. Another possible source of errors is related to feature point defects, e.g. matching of repeat MODIS images relies on surface contrast features (moraine deposits, ice mounds, etc.) that are usually scarce on the ice shelves. In addition, the accumulated snow pack can bury surface contrast features. Moreover, the vertical variations caused by oceanic tides and basal melt can cause erroneous matches near the eastern edges of the ice shelf (Yu et al., 2010).

The limitations discussed above can impact the accuracy of the surface velocity estimation for ice shelves. There are no stable bare rocks in the study area, thus testing objects outside the study area are selected for the error analysis. To quantify the uncertainties of the results in applying COSI-Corr to MODIS L1B images, 25 matching points are selected and investigated, the RMSE of the matching measurements in both W-E and S-N directions over stable bare rocks is given in Table 2 . Results indicate that the average of the errors is approximately $\pm 79 \mathrm{~m}$ which are slightly higher than the results re-

Table 2 Root mean square errors of displacement measurements obtained using the cross-correlation coefficient (CCC) over stable bare rocks

\begin{tabular}{ccc}
\hline Image pairs & RMSE $_{\mathrm{E}-\mathrm{W}}(\mathrm{m})$ & RMSE $_{\mathrm{S}-\mathrm{N}}(\mathrm{m})$ \\
\hline $2000 / 2003$ & 54 & 62 \\
$2003 / 2006$ & 46 & 56 \\
$2006 / 2009$ & 61 & 71 \\
$2009 / 2012$ & 47 & 52 \\
Mean & 52 & 60 \\
\hline
\end{tabular}


ported by Haug et al. (2010) using the OC based on MODIS. This may be because the CCC has more erroneous matches. However, taking into account the fact that the study area has a vast expanse of approximately $46,000 \mathrm{~km}^{2}$, and a relatively high flow rate (in a range between 140 and $736 \mathrm{~m} / \mathrm{a}$ ), the uncertainties still meet the requirements for analysing the spatiotemporal variations of surface velocity. In short, the method of using CCC and MODIS images is suitable for the studies on the spatiotemporal variations of ice shelf movement on a large scale.

\section{Results}

\subsection{Spatial pattern of surface velocities}

The surface velocity fields of ice shelves in the northern Antarctic Peninsula over four periods are obtained by the cross-correlation of four sets of images. The results show that the ice flow directions generally match the peninsula's pattern and the crevasse distribution. Ice mainly flows eastward into the Weddell Sea (Figure 3).

As observed, the spatial pattern of the velocity field exhibits an increasing trend from the western grounding line to the maximum at the middle part of the ice shelf front on Larsen $\mathrm{C}$, and the velocity field shows relatively higher values in its southerly neighboring ice shelf
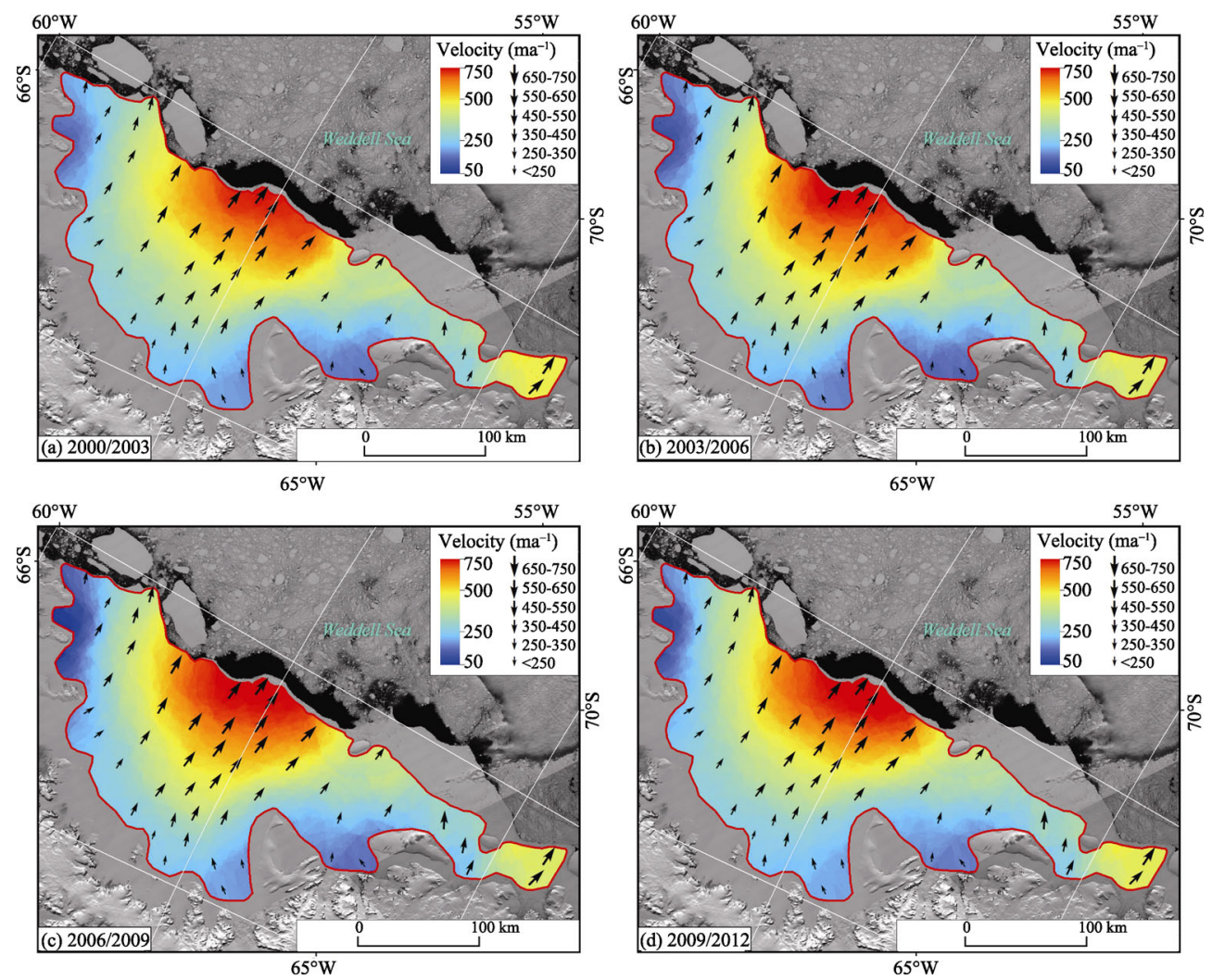

Figure 3 Spatial pattern of surface velocity of ice shelves in the northern Antarctic Peninsula during four periods (a. 2000/2003, b. 2003/2006, c. 2006/2009, and d. 2009/2012). The arrows in black indicate flow vector with quantities and directions at the 50 sample points with the best contrast on MODIS images (Figure 4). The underlying images are MODIS mosaic in 2006. 
(e.g. Smith Inlet). As expected, we find the highest velocities at the central to outer part of the Larsen $\mathrm{C}$ ice shelf, with velocities exceeding $700 \mathrm{ma}^{-1}$. The absolute velocity value at those locations varies greatly from $141 \mathrm{ma}^{-1}$ at one location to up to $736 \mathrm{ma}^{-1}$ at another location, indicating the heterogeneity of the spatial distribution of the speed field of the ice shelves. Within the area of collectively homogeneous flow pattern, some irregularities can still be identified that correspond to fractures spatially, together with a remarkable imprint indicated on the ice motion field where rifts lie on the Hollick-Kenyon Pen. and the Hearst I. (Figure 2). In addition, a few high velocity-gradient zones are also present, for example, from the Mill Inlet and Cabinet Inlet to Bawden Ice Rise. From the Mobiloil Inlet and Smith Inlet to outer part of ice shelf, the velocities between 100 and $150 \mathrm{ma}^{-1}$ are higher than those of the neighboring regions.

\subsection{Temporal variations in surface velocities}

Fifty sample points with the best contrast almost evenly distributed across the study area (Figure 3) are selected for quantitative analysis and they are marked in Figure 4. Figure 5 shows the velocity values derived from various periods at each location. We can see that at most locations, the ice speed increased from 2000-2003 to 2009-2012 (Figure 5).

More specifically, the mean velocity of 50 sample points in $2000-2003$ is $397 \mathrm{ma}^{-1}$ with the range between 141 and $711 \mathrm{ma}^{-1}$. Meanwhile, the mean velocity in 2003-2006 is 424 $\mathrm{ma}^{-1}$, and the range is between 158 to $709 \mathrm{ma}^{-1}$. The mean velocity in 2006-2009 is 444 $\mathrm{ma}^{-1}$ with the range between 175 to $706 \mathrm{ma}^{-1}$. The mean velocity in 2009-2012 is $445 \mathrm{ma}^{-1}$ and the range is between 183 to $736 \mathrm{ma}^{-1}$ (Figure 5). Results show that the ice flows relatively slowly in the inner regions of the ice shelf, e.g., the five sample points $(31,36,37,43$

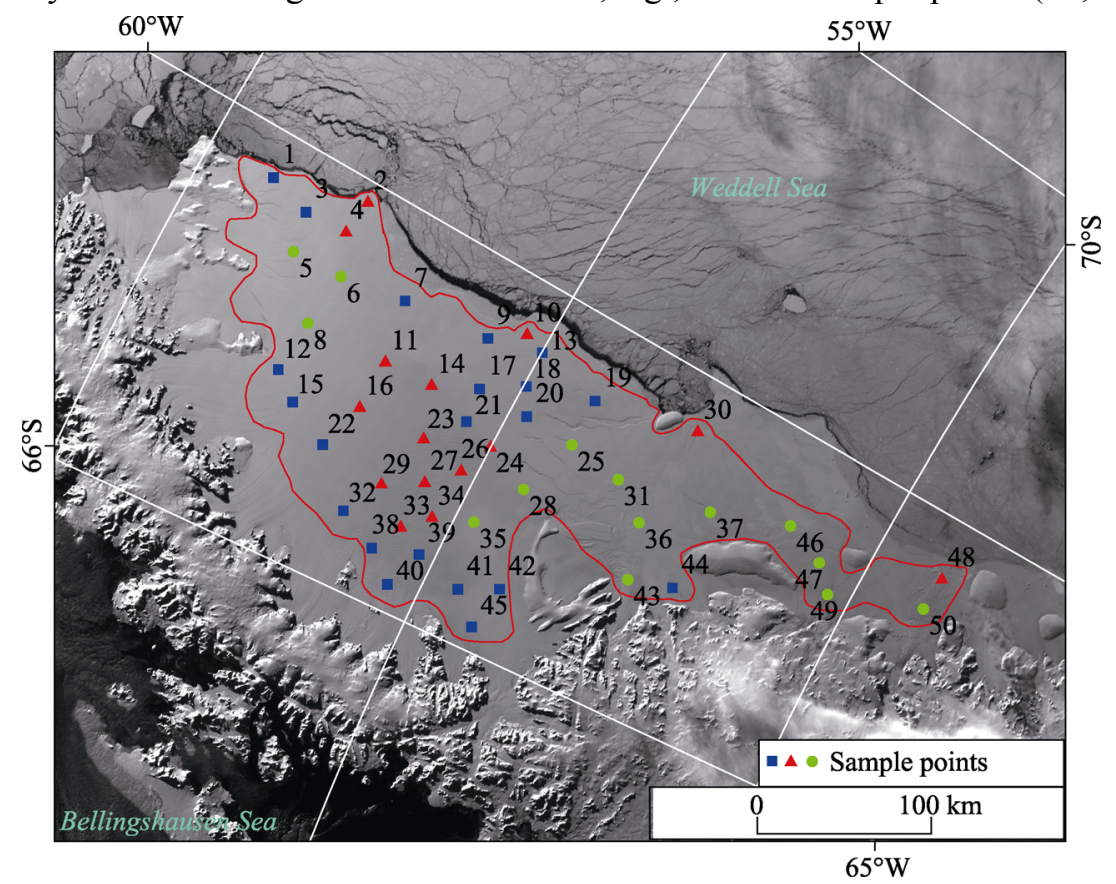

Figure 4 Sketch map of 50 sample points. The ice at the sample points in blue shows a continuous acceleration; at the sample points in red shows that there is not any significant change in velocity; and at the sample points in green shows a deceleration from the period 2006-2009 to the period 2009-2012. The underlying images are MODIS mosaic in 2009. 


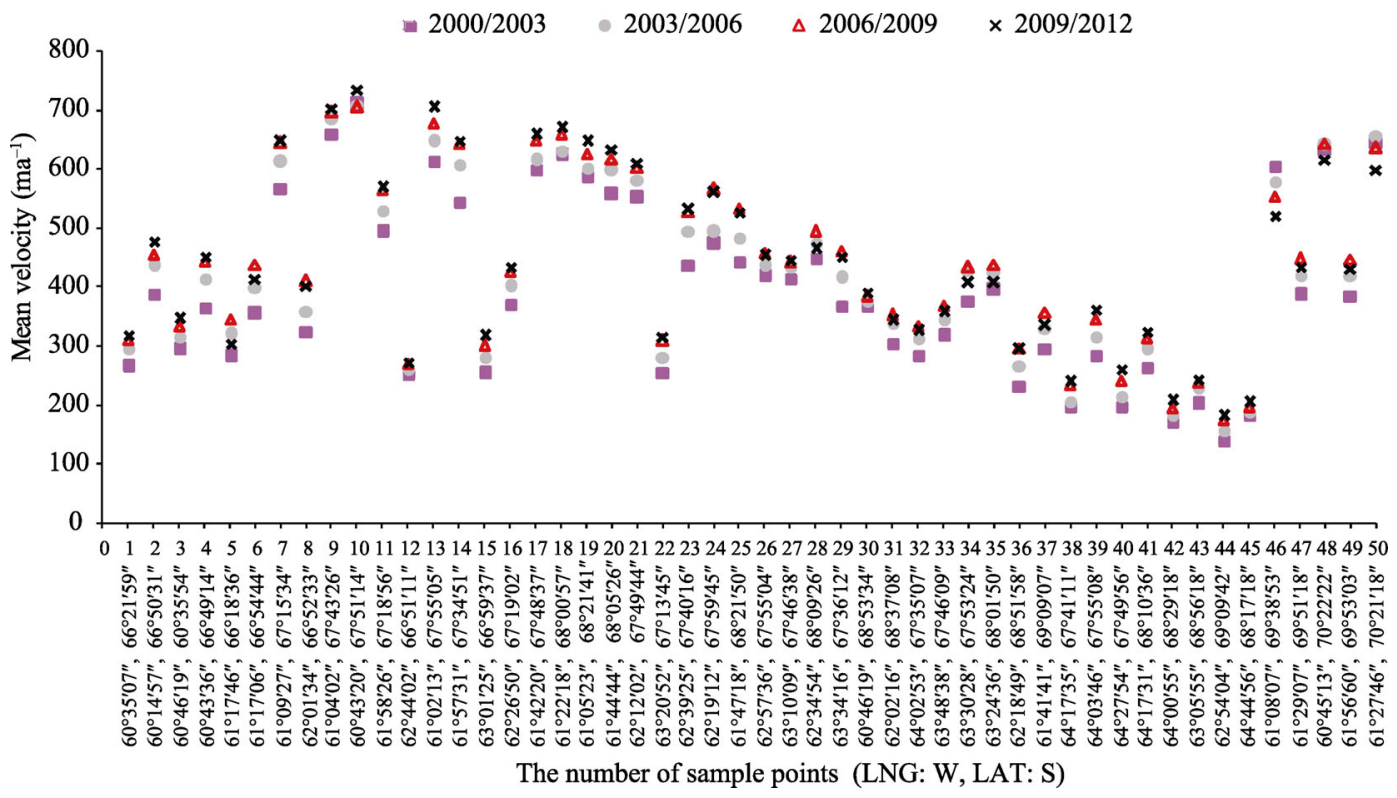

Figure 5 The mean velocity of 50 sample points with latitude and longitude during four periods

and 44) in the Hollick-Kenyon Pen. and Hearst I. (e.g. mean velocity is $236-285 \mathrm{ma}^{-1}$ ). The three sample points (1, 3 and 5) in the northern Larsen C Ice Shelf show even lower velocity. In contrast, the sample points $(9,10,13$ and 18) in the middle section of the ice front on Larsen C Ice Shelf have higher velocities of 653-704 $\mathrm{ma}^{-1}$, and the sample points (48 and 50) in the Smith Inlet also have high velocities of 608-649 $\mathrm{ma}^{-1}$.

Overall, temporal changes in surface velocities at the 50 sample points show continuous acceleration from 2000 to 2012. They increased by up to $12 \%$ from $2000-2003$ to 2009-2012. The overall velocity on ice shelf inlet and outer part of Larsen C shows a continuous increase. The Mobiloil inlet, Mill inlet, etc. did not appear to respond to the acceleration and deceleration of the eastern ice shelf edge, and ice at points 22 and 40, etc. in this region shows a continuous and steady rate of acceleration. The trend of the velocities on the eastern ice shelf edge (at sample points 10, 30 and 48) is inconclusive, due to effects of oceanic tides and basal melt. The temporal variations show a widespread deceleration on the southern Larsen C Ice Shelf from 2006-2009 to 2009-2012, as well as its neighboring ice shelves (e.g. the Smith Inlet). The ice deceleration observed in these regions is consistent with the study by Khazendar et al. (2011). Ice at 10 points in the southern Larsen $\mathrm{C}$ and its neighboring ice shelves has been decelerating from 2006-2009 to 2009-2012 by up to $2.5 \%$. Overall, temporal changes in surface velocities show a continuous acceleration from 2000 to 2012 (Figure 6), whereas the acceleration rate during 2000-2009 is relatively higher

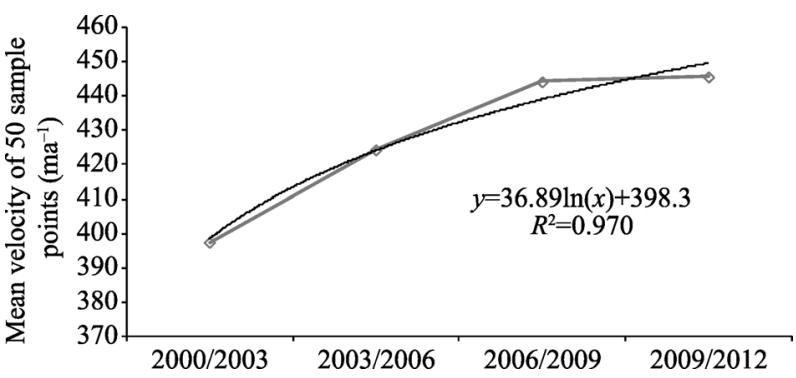

Figure 6 Variation of mean velocity of 50 sample points during 2000-2012 than that during 2009-2012. 


\section{Discussion}

The matching method is one of the important factors that impact the uncertainty of the surface velocity derived from MODIS images. Heid and Kääb (2012) compared and evaluated different existing matching methods and showed that for areas with high visual contrast on optical images, NCC performs better than other methods with slightly lower RMSE. However, Haug et al. (2010) reported that NCC produces more incorrect matches than OC but with similar RMSE, and the uncertainty of NCC and OC is $\pm 21.5 \mathrm{~m}$ and $\pm 21.8 \mathrm{~m}$, respectively. CCC is often used to derive glacier velocity field due to the algorithm's simplicity (Huang and Li, 2011). The main rule of CCC is similar to NCC, thus this matching method is also suitable for deriving velocity in areas with good visual contrast on images (e.g. on open areas of ice shelf where there are significant flowing textures and large-scale structural features). In addition, for areas with relatively high velocity, using CCC and MODIS images can get acceptable errors, with the RMSE being approximately $\pm 79 \mathrm{~m}$ which is just slightly higher than the results reported by Haug et al. (2010) by using the OC. We identify the spatiotemporal patterns of surface movement of ice shelves for long-term velocity estimation on a large scale. Thus, the CCC meets the requirements for analysing the spatiotemporal variations on ice shelves in the northern Antarctic Peninsula, which can serve as a supplement to the existing methods.

In line with existing studies, and comparing with the Larsen B ice shelf, our study shows a continuous but moderate increase in speed on large portions of the study area. The overall velocity over the whole study area increased approximately by $12 \%$ from 2000 to 2012 , while the rate of acceleration in the northern sector is higher as compared to the southern sector. The estimated differences in speed between 2000 and 2012 can be divided into three groups (Figure 4): 1) Northern sector: This region shows a continuous acceleration during the observation period, possibly due to a reduction in backstress from the Bawden Ice Rise and/or the erosion of marine ice formerly suturing parallel flow bands together (McGrath et al., 2012). While the essential reason for the drastic acceleration is related to the condition that this region has progressively thinned, the elevation of the Larsen $\mathrm{C}$ has lowered at a rate of 0.06-0.09 $\mathrm{ma}^{-1}$ during 1978-2008 (McGrath et al., 2012), and the greatest lowering occurred in the northern sector of Larsen C (Fricker and Padman, 2012; Shepherd et al., 2003). This lowering circumstance is dominated by the increased melt-water production/refreezing (Holland et al., 2011) rather than increased basal melting. 2) Southern sector: Many large surface crevasses originate at Kenyon Peninsula and end at Gipps Ice Rise, this region and neighboring ice shelf extending to the south show an overall acceleration during the observation period. Beyond our expectation, the present estimated results show that the southern sector slowed down slightly during recent years. This deceleration should be related to the increase of backstress caused by the ice fronts which tend to be more stabilized recently. Additionally, the southern sector is a more complex region, with the overall surface elevation showing a slight increase during the period 1993-2005. (Fricker and Padman, 2012). 3) The floating ice region near the grounding line: We mask out the grounding line area due to the coarse spatial resolution of MODIS images. This region mainly covers Cabinet Inlet, Mill Inlet, Mobiloil Inlet, Revelle Inlet and Smith Inlet, etc. The northern sector of the Larsen $\mathrm{C}$ accelerated by $15 \%$ between 2000 and 2006, and a further acceleration of $6 \%-8 \%$ between 2006 and 2008 at the nearby grounding line areas (e.g. Cabinet Inlet) (Khazendar et 
al., 2011). Smith Inlet shows a deceleration during recent years. The temporal characteristics of surface velocity in the floating ice region near the grounding line show a continuous and steady rate of acceleration, where did not appear to respond to the acceleration and deceleration of the eastern ice shelf edge. This acceleration is possibly caused by reduction of backstress and increasing of longitudinal stress with downstream ice shelves progressively thinned (Scambos et al., 2003). Despite the ice shelves in the northern Antarctic Peninsula will not face imminent collapse (Holland et al., 2015), they are undergoing significant acceleration in speed which is spatially related to fracture and thinning (Khazendar et al., 2011). The continuous acceleration in speed and thinning in elevation, increasing basal melt due to warming upper-ocean temperatures (Nicholls et al., 2004), and the meltwater-driven crevasse propagation are the main mechanism for the rapid collapse of ice shelf (Rott et al., 1996; Scambos et al., 2000, 2009). It presages destabilization if Larsen C is to evolve similarly to Larsen B (Griggs and Bamber, 2009).

\section{Conclusions}

This study estimates the surface velocities in ice shelves of the northern Antarctic Peninsula using COSI-Corr module and MODIS images in 2000, 2003, 2006, 2009 and 2012, respectively. The results show that the overall velocity of ice shelves is relatively high due to the extremely large ice flux, and it has a mean velocity of approximately $400 \mathrm{ma}^{-1}$ with a maximum of $736 \mathrm{ma}^{-1}$, making it one of the fastest-moving areas in the Antarctic Peninsula. The spatial pattern of the velocity field shows that velocities increase from the western grounding line to a maximum of approximately $700 \mathrm{ma}^{-1}$ at the middle region of the ice front on Larsen C Ice Shelf and the ice flows relatively slowly in the inner parts. Temporal changes of surface velocities show a continuous acceleration from 2000 to 2012, and the acceleration rate from 2000-2003 to 2006-2009 is greater than that from 2006-2009 to 2009-2012. However, the velocity on the southern Larsen C Ice Shelf and the Smith Inlet from 2009 to 2012 shows a deceleration. The method of using CCC and MODIS images to derive ice velocity field for ice shelves only provides moderate accuracy due to the simplicity of cross-correlation algorithm, feature point defects and geolocation errors, etc. However, these uncertainties still meet the requirements for analysing the spatiotemporal variations of surface velocity. In short, the method of using CCC and MODIS images is suitable for large-scale monitoring of ice velocities in the Antarctic ice shelves, which is a valuable complement to other methods such as INSAR, GPS and high-resolution optical image feature tracking, etc.

\section{References}

Ahn Y, Howat I M, 2010. Efficient automated glacier surface velocity measurement from repeat images using multi-image/multichip and null exclusion feature tracking. IEEE Transactions on Geoscience and Remote Sensing, 49(8): 2838-2846.

Ayoub F, Leprince S, Avouac J P, 2009. Co-registration and correlation of aerial photographs for ground deformation measurements. ISPRS Journal of Photogrammetry and Remote Sensing, 64(6): 551-560.

Berthier E, Raup B, Scambos T, 2003. New velocity map and mass-balance estimate of Mertz Glacier, East Antarctica, derived from Landsat sequential imagery. Journal of Glaciology, 49(167): 503-511.

Bindschadler R A, Fahnestock M A, Skvarca P et al., 1994. Surface-velocity field of the northern Larsen Ice Shelf, Antarctica. Annals of Glaciology, 20(1): 319-326. 
Broeke M V D, 2005. Strong surface melting preceded collapse of Antarctic Peninsula ice. Geophysical Research Letters, 32(12): L12185.

Cook A J, Vaughan D G, 2010. Overview of areal changes of the ice shelves on the Antarctic Peninsula over the past 50 years. The Cryosphere, 4(1): 77-98.

Cook A J, Murray T, Luckman A et al., 2012. A new 100-m Digital Elevation Model of the Antarctic Peninsula derived from ASTER Global DEM: Methods and accuracy assessment. Earth System Science Data, 4(1): 129-142.

Erten E, Chesnokova O, Hajnsek I et al., 2012. Glacier surface velocity measure based on polarimetric tracking. Geoscience and Remote Sensing Symposium (IGARSS), 2012 IEEE International, 12: 3126-3129.

Evans A N, 2000. Glacier surface motion computation from digital image sequences. IEEE Transactions on Geoscience and Remote Sensing, 38(2): 1064-1072.

Fitch A J, Kadyrov A, Christmas W J et al., 2002. Orientation Correlation, in: British Machine Vision Conference, 133-142.

Fricker H A, Padman L, 2012. Thirty years of elevation change on Antarctic Peninsula ice shelves from multimission satellite radar altimetry. Journal of Geophysical Research, 117: C02026.

Glasser N F, Kulessa B, Luckman A et al., 2009. Surface structure and stability of the Larsen C ice shelf, Antarctic Peninsula. Journal of Glaciology, 55(191): 400-410.

Griggs J A, Bamber J L, 2009. Ice shelf thickness over Larsen C, Antarctica, derived from satellite altimetry. Geophysical Research Letters, 36(19): L19501.

Haran T, Bohlander J, Scambos T A et al., 2005. MODIS mosaic of Antarctica (MOA) image map, digital media, Natl. National Snow and Ice Data Center (US), Boulder, Colo.

Haug T, Kääb A, Skvarca P, 2010. Monitoring ice shelf velocities from repeat MODIS and Landsat data-a method study on the Larsen $\mathrm{C}$ ice shelf, Antarctic Peninsula, and 10 other ice shelves around Antarctica. The Cryosphere, 4(2): 161-178.

Heid T, Kääb A, 2012. Evaluation of existing image matching methods for deriving glacier surface displacements globally from optical satellite imagery. Remote Sensing of Environment, 118: 339-355.

Hirt C, Filmer M, Featherstone W, 2010. Comparison and validation of the recent freely available ASTER-GDEM ver1, SRTM ver4.1 and GEODATA DEM-9S ver3 digital elevation models over Australia. Australian Journal of Earth Sciences, 57(3): 337-347.

Holland P R, Brisbourne A, Corr H F J et al., 2015. Oceanic and atmospheric forcing of Larsen C Ice-Shelf thinning. The Cryosphere, 9(3): 1005-1024.

Holland P R, Corr H F J, Pritchard H D et al., 2011. The air content of Larsen Ice Shelf. Geophysical Research Letters, 38(10): L10503.

Huang L, Li Z, 2011. Comparison of SAR and optical data in deriving glacier velocity with feature tracking. International Journal of Remote Sensing, 32(10): 2681-2698.

Jansen D, Kulessa B, Sammonds P R et al., 2010. Present stability of the Larsen C ice shelf, Antarctic Peninsula. Journal of Glaciology, 56(198): 593-600.

Kaufmann V, Ladstädter R, 2003. Quantitative analysis of rock glacier creep by means of digital photogrammetry using multitemporal aerial photographs: Two case studies in the Austrian Alps. Proceedings of the 8th International Conference on Permafrost, 525-530.

Kääb A, Vollmer M, 2000. Surface geometry, thickness changes and flow fields on creeping mountain permafrost: Automatic extraction by digital image analysis. Permafrost and Periglacial Processes, 11(4): 315-326.

Ke C Q, Kou C, Ludwig R et al., 2013. Glacier velocity measurements in the eastern Yigong Zangbo basin, Tibet, China. Journal of Glaciology, 59(218): 1060-1068.

Khazendar A, Rignot E, Larour E, 2011. Acceleration and spatial rheology of Larsen C Ice Shelf, Antarctic Peninsula. Geophysical Research Letters, 38(9): L09502.

Leprince S, Barbot S, Ayoub F et al., 2007. Automatic and precise ortho-rectification, coregistration, and subpixel correlation of satellite images, application to ground deformation measurements. IEEE International Symposium on Geoscience and Remote Sensing, 45(6): 1529-1558.

Manson R, Coleman R, Morgan P et al., 2000. Ice velocities of the Lambert Glacier from static GPS observations. Earth, Planets and Space, 52(11):1031-1036.

McClellan J, Schafer R, Yoder M, 2003. Signal Processing First. Pearson Prentice Hall: Pearson Education, Inc.0-13-120265-0.

McGrath D, Steffen K, Rajaram H et al., 2012. Basal crevasses on the Larsen C Ice Shelf, Antarctica: Implications for meltwater ponding and hydrofracture. Geophysical Research Letters, 39(16): L16504.

Morris E M, Vaughan D G, 2003. Spatial and temporal variation of surface temperature on the Antarctic Peninsula and the limit of viability of ice shelves, in Antarctic Peninsula Climate Variability, Historical and 
Paleoenvironmental Perspectives. In: Domack E et al. (eds.). Antarct. Res. Ser., 79: 61-68, AGU, Washington, D. C.

Nakamura K, Doi K, Shibuya K, 2007. Estimation of seasonal changes in the flow of Shirase Glacier using JERS-1/SAR image correlation. Polar Science, 1(2): 73-83.

NASAG, 1996. Landsat 7 System Specification, NASA Goddard Space Flight Center.

Nicholls K W, Pudsey C J, Morris P, 2004. Summertime water masses off the northern Larsen C Ice Shelf, Antarctica. Geophysical Research Letters, 31(9): L09309.

Osmanoglu B, Braun M, Hock R et al., 2013. Surface velocity and ice discharge of the ice cap on King George Island, Antarctica, Annals of Glaciology, 54(63): 111-119.

Rack W, Doake C S M, Rott H et al., 2000. Interferometric analysis of the deformation pattern of the northern Larsen Ice Shelf, Antarctic Peninsula, compared to field measurements and numerical modeling. Annals of Glaciology, 31(1): 205-210.

Rack W, Rott H, 2004. Pattern of retreat and disintegration of the Larsen B ice shelf, Antarctic Peninsula. Annals of Glaciology, 39(1): 505-510.

Rack W, Rott H, Siegel A et al., 1999. The motion field of northern Larsen Ice Shelf, Antarctic Peninsula, derived from satellite imagery. Annals of Glaciology, 29(1): 261-266.

Rignot E, Mouginot J, Scheuchl B, 2011. Ice flow of the Antarctic ice sheet. Science, 333(9): 1427-1430.

Roland C W, Jason L B, 2013. Pine Island Glacier (Antarctica) velocities from Landsat 7 images between 2001 and 2011: FFT-based image correlation for images with data gaps. Journal of Glaciology, 59(215): 572-582.

Rosenau R, Dietrich R, Baessler M, 2012. Temporal flow variations of major outlet glaciers in Greenland using Landsat data. IEEE International Symposium on Geoscience and Remote Sensing (IGARSS), 2012 IEEE International, 23: 1557-1560.

Rott H, Müller F, Nagler T et al., 2011. The imbalance of glaciers after disintegration of Larsen-B ice shelf, Antarctic Peninsula. The Cryosphere, 5(1): 125-134.

Rott H, Skvarca P, Nagler T, 1996. Rapid collapse of northern Larsen Ice Shelf, Antarctica. Science, 271(5250): 788-792.

Scambos T A, Berthier E, Shuman C A, 2011. The triggering of subglacial lake drainage during rapid glacier drawdown: Crane Glacier, Antarctic Peninsula. Annals of Glaciology, 52(59): 74-82.

Scambos T A, Fricke C C, Liu J et al., 2009. Ice shelf disintegration by plate bending and hydro-fracture: Satellite observations and model results of the 2008 Wilkins ice shelf break-ups. Earth and Planetary Science Letters, 280(1): 51-60.

Scambos T A, Haran T M, Fahnestock M A et al., 2007. MODIS-based Mosaic of Antarctica (MOA) data sets: Continentwide surface morphology and snow grain size. Remote Senseing of Environment, 111(2): $242-257$.

Scambos T A, Hulbe C, Fahnestock M, 2003. Climate-induced ice shelf disintegration in the Antarctic Peninsula, in Antarctic Peninsula Climate Variability: Historical and Paleoenvironmental Perspectives. Domack E et al. (ed.). Washington, D. C.: AGU, 79-92.

Scheuchl B, Mouginot J, Rignot E et al., 2012. Ice velocity changes in the Ross and Ronne sectors observed using satellite radar data from 1997 and 2009. The Cryosphere, 6(3): 1019-1030.

Shepherd A, Wingham D, Payne T et al., 2003. Larsen ice shelf has progressively thinned. Science, 302(5646): 856-859.

Skvarca P, 1993. Fast recession of the northern Larsen Ice Shelf monitored by space images. Annals of Glaciology, 17: 317-321.

Strozzi T, Kouraev A, Wiesmann A et al., 2008. Estimation of Arctic glacier motion with satellite L-band SAR data. Remote Sensing of Environment, 112(3): 636-645.

Testut L, Hurd R, Coleman R et al., 2003. Comparison between computed balance velocities and GPS measurements in the Lambert Glacier basin, East Antarctica. Annals of Glaciology, 37(1): 337-343.

Tiwari R K, Gupta R P, Arora M K, 2014. Estimation of surface ice velocity of Chhota-Shigri glacier using sub-pixel ASTER image correlation. Current Science, 106(6): 853-859.

Vaughan D V, Marshall G J, Connolley W M et al., 2003. Recent rapid regional climate warming on the Antarctic Peninsula. Climatic Change, 60(3): 243-274.

Wolfe R, Nishihama M, Fleig A et al., 2002. Achieving sub-pixel geolocation accuracy in support of MODIS land science. Remote Sensing of Environment, 83(1): 31-49.

Xu J L, Zhang S Q, Han H D et al., 2011. Change of the surface velocity of Koxkar Baxi Glacier interpreted from remote sensing data, Tianshan Mountains. Journal of Glaciology and Geocryology, 33(2): 268-275. (in Chinese)

Yu J, Liu H X, Jezek K C et al., 2010. Analysis of velocity field, mass balance, and basal melt of the Lambert Glacier-Amery Ice Shelf system by incorporating Radarsat SAR interferometry and ICESat laser altimetry measurements. Journal of Geophysical Research, 115(11): 11-12. 